\title{
GROWING A NEW GENERATION
}

\author{
PROMOTING SELF-REFLECTION THROUGH \\ PEER OBSERVATION
}

Allison Boye, Micah Meixner, Texas Tech University

Many faculty developers understand the value of self-reflection in effective teaching and aim to cultivate the practice in their programming. However, many instructors regard peer observation as punitive or evaluative in nature and overlook how the practice can promote thoughtful self-reflection by the observer. This chapter outlines a model of group peer observation that supports introspection and community, thereby transforming that negative perception. We discuss how the process promotes cross-disciplinary open-door teaching and reflective practice in teaching improvement and how faculty developers from institutions and programs of all sizes can help nurture that growth.

In our work as graduate student developers facilitating an intensive fellowship program at Texas Tech University, the Teaching Effectiveness And Career enHancement (TEACH) program, we are constantly searching for ways to help new instructors improve their teaching and encourage them to engage in teaching as reflective practice. Reflection is a core value of our program, and we try to incorporate it into virtually everything our TEACH fellows do in the hope that it will become a habit that they take with them into their careers, not just something they engage in for the two semesters while they are working with us. Teaching so often takes place behind closed doors, so we strive to foster a culture of collegiality and open-door teaching.

We expect a significant amount of work from our fellows, including extensive teaching portfolios and scholarship of teaching and learning 
(SoTL) projects, twenty hours of workshop attendance, and having consultants videotape their classes; each element asks for self-reflection in some way. Nevertheless, we felt that there was room for improvement and so introduced a peer observation element. Now in its third year, we have found peer observation to be effective in building community as well as fostering self-reflection, and it has become one of the most popular elements of the program. Moreover, it has helped instructors open the closed doors not only of their classrooms, but also of their disciplines, and discover that they can learn a great deal by talking about teaching with colleagues from across the university.

\section{A Brief Overview of the Literature}

A study of the literature provided resounding support for the addition of peer observation to the program. Many institutions employ evaluative teaching observations in the tenure review process, and many of these same institutions support peer observation to inform teaching development (DeZure, 1993; Millis, 1992, 1999; Richardson, 2000; Weimar, 1990; Wilkerson \& Lewis, 2002). Nonevaluative peer observation is also cited as an important element in increased teaching effectiveness (Beaty, 1999; Chism, 1999; DeZure, 1993; Millis, 1992).

In the discussion of teaching observations for developmental purposes, the impact of reflection is continually emphasized as key to the success of the exercise. Findings on reflection suggest that instructors who reflect on their teaching and engage in dialogue about their teaching with colleagues, administrators, and faculty developers show continued or increased teaching effectiveness (Bell, 2001; Brookfield, 1995; Bullough \& Gitlin, 1991; Cosh, 1999; Hammersley-Fletcher \& Orsmond, 2005; Loughran, 2002; Wilkerson \& Lewis, 2002). In addition, the collegial dialogue that frequently results from peer observation often prompts the observer to reflect on his or her own teaching (Brookfield, 1995; Cosh, 1999; Hammersley-Fletcher \& Orsmond, 2005; Wilkerson \& Lewis, 2002).

Seasoned developers (Barnett, 1983; Millis, 1999; Weimar, 1990; Wilkerson \& Lewis, 2002) call attention to the tendency for classroom observations to be viewed as a punitive or negative experience, and they suggest peer observation and collegial conversation as ways in which this perception might be changed. To achieve an open culture, scholars such as Brookfield (1995), DeZure (1993), Millis (1992), and Shulman (2000) recommend encouraging classroom observations within the department as well as across the campus. These authors suggest that opening 
classrooms to observation by colleagues and other instructors is likely to establish a culture of reflective and improved teaching.

\section{Our Peer Observation Model}

Recognizing the power of reflection in conjunction with observation (Richardson, 2000), we use a reciprocal peer observation model that aims to emphasize the self-reflection of the observer rather than the feedback presented to the observed. Through the model, we endeavor to change the negative perception of observation as simply evaluative and instead support introspection and the collegiality of the peer relationship. In pursuit of those goals, we encourage observers to use the observation experience as an opportunity to think about their own teaching rather than an opportunity to critique their colleagues. Our experience has been that many fellows struggle with self-reflection in other TEACH program components, as they find it difficult to look at themselves from the outside in and contemplate the reasoning behind their classroom decisions. We therefore believe that putting them in an external position of observer, watching a peer in action, offers them another aperture through which they might gaze back at themselves and consider "Why don't I do that?" Or, "Do I do that too?"

TEACH fellows are assigned to groups of three to four that encompass similar and dissimilar disciplines as well as varying levels of experience. Although the groups change each semester, it is not unusual for at least two group members to be paired again in subsequent semesters. One fellow made the following comment about the benefit of continued partnership: "What was most encouraging was seeing the growth of one teacher the second semester that I observed her. I realized that I had grown significantly as well." (All participants quoted in this chapter gave permission to quote them.)

To dispel the idea that observations are conducted solely for evaluative purposes, we believe it is important for each instructor to experience all aspects of observation. After groups are assigned, each fellow must observe at least one other group member and be observed by at least one group member each semester. Brookfield (1995) asserts, "Peer observation must be reciprocal. If you are going to invite colleagues into your classrooms, it should be on the understanding that you'll return the favor by visiting theirs. All too often, peer observation reproduces the power dynamics on campus" (p. 85). Reciprocity helps diminish the stigma of evaluative observation and shifts the focus to a strengthened sense of collegial dialogue and association. Although only one observation is 
required, we encourage fellows to conduct multiple observations each semester, and at least three or four typically do so.

The act of simply going into a colleague's classroom to think about your own teaching helps show fellows that teaching does not have to be an isolated experience and furthers the program goal of cultivating an open-door teaching culture. The group follow-up discussion fosters collegiality and the idea that teaching does not have to be private or perfect. Many fellows appreciate the opportunity to observe others who are at the same level, in contrast to other models that highlight the observation of only excellent teaching (DeZure, 1993). In observing their peers, they are not intimidated and are therefore in a better position to observe and reflect on their own practices. As one fellow remarked in our survey, "It has been a very enlightening experience. I realized that we all have similar situations, problems, and students."

The interdisciplinary cohort also enables cross-disciplinary observation, and for many fellows, observing a class that is completely different from their own has been an eye-opening experience. In observing across disciplines, these new instructors are exposed to different modes of teaching, and they are forced to focus on the teaching without getting bogged down in the content because the content itself is unfamiliar (Beaty, 1999). Cross-disciplinary observation demonstrates that an open-door teaching culture does not have to be limited to one's own department; rather, there are universal issues surrounding teaching and learning that can extend well beyond the confines of a single discipline. One fellow noted in our 2008 survey, "It was fascinating to watch a class in a discipline so different from mine, one that was strongly lecture-based and yet still involved the class. I was impressed that such a large lecture could still require student input and involvement."

Because reflective teaching is something that we constantly promote with faculty and graduate students alike, we ask that each of the fellows submit a piece of postobservation reflective writing in response to a series of questions provided to them in their TEACH Program Handbook. Writing often serves as an instrument for guided reflection (Maas, 1991), and we therefore ask the fellows to respond to a handful of questions that encourage them to reflect on their experience as observers and their thinking about their teaching. In recognition of the fact that many inexperienced instructors might need a familiar location to begin their observations and reflection, and in spite of the fact that many instructors struggle with the seemingly visceral impulse to critique, we include questions such as, "What suggestions might you share with the instructor?" This question helps the instructors establish a basis of what they like or 
dislike in a classroom, and then more easily enter into reflection about their own teaching.

The fellows submit their written reflections to their consultant prior to any follow-up discussion. When they turn in a bulleted list or time line of the observation, we request that they more fully explain and reflect on their observations before sharing their write-up with the remainder of the group. We have seen considerable growth in rewritten statements. It has been our observation that the writing component is critical to the success of the peer observation process, as it is often through writing that these instructors begin to reflect and consider their own teaching, producing thoughtful insights like this one: "Witnessing B's class also made me consider the difference between process and end result. In other words, can it be effective to teach students in a manner that emphasizes the process rather than the end result? Perhaps the learning process may be more effective when the final result isn't always so obvious."

After everyone in the group has observed and been observed and has submitted reflective writing to one of the consultants, the group meets for a discussion with both the group members and consultants to share their reflective writings and engage in conversation about their ideas and observation experiences. Many fellows view this discussion as a significant part of the process that provides a forum to discuss their most intimate teaching concerns and challenges. As Bell (2001) states, "Truly collegial and developmental activities involving observation encourage shared critical reflection on real-life teaching experiencesand can lead to transformation of both perspective and practice" (p. 29). Most important, the group setting offers the fellows a safe haven and a support system for introspection. In this venue, young instructors can come to the liberating realization that teaching "is a learning process and I am not alone."

While many models of peer observation (Bell, 2001; HammersleyFletcher \& Orsmond, 2005; Millis, 1992, 1999) outline a process of observation based on a system of consultation before the observation, followed by the observation, and then a follow-up, we have elected not to include a preobservation consultation in our model. Though the value of preobservation consultations is indisputable, we decided that it might emphasize the evaluative rather than the reflective aspects of observation by focusing too much on what the observed person hopes to gain. In addition, the logistical implications of preobservation meetings in which the observation process is not always reciprocal could potentially create a scheduling ordeal as well as overwhelm fellows with even more commitments on top of the other highly rigorous program requirements. 
Allen (1991) asserts that the notion of reflective teaching "has the advantage of being relatively uncomplicated" (p. 314), drawing on Posner's (1989) model, which indicates that experience plus reflection equals growth. Our model of reflective teaching, if encapsulated into a similar formula, would be similarly uncomplicated: experience plus observation plus dialogue can foster reflection, which can lead to growth. We offer a purposefully simple paradigm because we maintain that growth does not necessitate complexity, particularly for novice teachers. Furthermore, we do not expect that all reflection will be critical reflection for these young instructors, for, as Brookfield (1995) agrees, "just because reflection is not critical does not mean it is unimportant or unnecessary" (p. 8). For instance, during an observation, some instructors might realize that it is valuable to repeat questions for students, or ask students to put away their cell phones, or as one fellow realized, simply "slow down and make sure all the details are known." For these instructors, or even seasoned instructors, those are valuable realizations; it is reflection, and it has led to growth.

\section{The Role of the Faculty Developer}

Our role as faculty developers within this model is primarily supportive. We assist with essential logistics: collecting schedules, making introductions, or stepping in on the rare occasion when groups experience difficulties scheduling their observations of one another. In creating groups, we must make sure that class times do not conflict and that every member of a group will have the opportunity to observe at least one other peer. However, we also work to create groups that we think will be a good fit with one another based on what we know about experience, discipline, and personality. Sometimes that means matching more experienced instructors with newer instructors, or teachers who favor traditional methods with those who like to experiment. Of course, we cannot ultimately predict group dynamics, but our goal is to make the process as free as possible from conflict while exposing the instructors to new experiences. So far this approach has proven successful. For instance, a shy music instructor whose students were talking throughout her classes experienced an epiphany by observing a gregarious theater instructor speak out and tell her students to quiet down; at that moment, she finally realized that she too could "manage a tranquil environment for a class and stop unnecessary talking among students while the instructor speaks without hurting students' feelings." That moment was made possible by her cross-disciplinary peer observation experience with an instructor she might otherwise have never met. 
During the observation process itself, we provide guidance to instructors in the form of the questions that we ask them to ponder as they reflect on the experience as well as classroom elements, such as content, classroom management, student engagement, and delivery and communication, they might consider during their classroom visit (Exhibit 2.1). Because our clients are primarily novice instructors working outside their discipline, we recognize the importance of providing them with structure and focus for the experience so that they have a foundation for their observation and reflection.

\section{Exhibit 2.I Peer Observation Reflective Questions and Guidelines}

- What did this observation help you recognize about your own teaching? Did you identify with anything that happened in the class? Did this experience make you want to change or implement something new in your own classroom?

- In conducting this observation, what thoughts did you have about the practice of teaching and learning in general? For instance, did your observation inform your thinking about big picture issues like classroom management or student engagement? Did you change your mind about anything, or confirm beliefs you already had?

- What did the instructor do particularly well?

- What suggestions or ideas might you share with the instructor?

- If you observed someone in a discipline different from your own, what was that experience like?

Here are some general matters you might consider as you observe your peers in the classroom (yes, there is a lot that goes into teaching!). You don't need to address ALL or any of these; these are just to help you focus during your observation and to assist you in your reflections on teaching. And you can certainly think about issues that are not included here!

Content: Content knowledge; answering questions; variety; challenging and stimulating; use of examples and analogies; clarity; application; synthesis of information and connections; organization

Classroom management: Student attention; student participation; student preparation; student civility

Student engagement: Instructor enthusiasm; rapport with students; active involvement; asking questions; discussion; class activities; student participation

Delivery and communication: Eye contact; clarity; volume; movement; pace; visuals; technology 
Following the observations, the consultants are present to help facilitate follow-up discussion. We help initiate the discussion and, more important, are there to promote deeper reflection during the discussion and shift the focus away from evaluation when necessary. The impulse to evaluate when observing is a natural one, so during the group discussion, we strive to steer the instructors gently back toward self-evaluation and reflection, often by asking questions as simple as, "So what does that make you think about your own teaching? Is that something you would be interested in trying?" or "How does this influence your thoughts on ...?" In addition, participating in the discussions benefits us as consultants by allowing us to get to know the fellows on a deeper level.

The group discussion and dynamic are vital to promoting self-reflection, for much of the reflection begins to happen in the dialogue among peers and consultants (Maas, 1991). Although the instructors have engaged in reflection during the writing process, that reflection truly blossoms as they bounce ideas off one another and begin to think of things that occurred to them during dialogue. As one fellow stated, "I think the most valuable part of the process was when the peer group sat down together and talked about the things that they learned from each other."

\section{Assessment}

Several strategies have been used to determine the success of our peer observation model as a component of the TEACH program, and in general we have received a very positive response from our fellows. One method of assessment is a year-end anonymous online survey with qualitative and quantitative questions designed to elicit feedback on the peer observation process. Data were gathered from two cohorts over the course of two academic years (Table 2.1). In 2009, the cohort contained an unusually high number of graduating fellows who were understandably busy at the end of the year, which could explain the lower response rate for that year.

Significantly more ( 82 percent) of the 2009 respondents indicated that they felt engaged in community with other fellows, compared to only 44 percent of the 2008 respondents. Similarly, 82 percent of the 2009 respondents compared to 56 percent of the 2008 respondents claimed to have enjoyed the opportunity to compare another discipline to their own and to focus solely on teaching rather than content. We attribute these dramatic increases to the expansion of the group dynamic. We expanded the observation model from pairs to groups in 2008 and 2009, realizing that the more complicated logistics were worth the significant benefits. 


\section{Table 2.I Peer Observation Participant Quantitative Survey Responses}

\begin{tabular}{|c|c|c|}
\hline & 2008 & 2009 \\
\hline Regarding the Peer Observation Process & $(N=16)$ & $(N=11)$ \\
\hline $\begin{array}{l}\text { Felt more engaged in community with other TEACH } \\
\text { fellows }\end{array}$ & $44 \%$ & $82 \%$ \\
\hline Gained insight into my teaching & 38 & 82 \\
\hline $\begin{array}{l}\text { Took away some good ideas to try in my own } \\
\text { teaching }\end{array}$ & 69 & 82 \\
\hline $\begin{array}{l}\text { Engaged in critical reflection about teaching in } \\
\text { general }\end{array}$ & 38 & 91 \\
\hline Felt more confident in my teaching & 38 & 73 \\
\hline Felt discouraged about my teaching & 0 & 9 \\
\hline $\begin{array}{l}\text { Enjoyed the opportunity to watch someone else } \\
\text { teach }\end{array}$ & 81 & 73 \\
\hline $\begin{array}{l}\text { Enjoyed the opportunity to compare another disci- } \\
\text { pline to my own and just focus on teaching rather } \\
\text { than content }\end{array}$ & 56 & 82 \\
\hline Found it difficult to observe another discipline & NA & 0 \\
\hline Felt inspired to do more in my teaching & NA & 64 \\
\hline $\begin{array}{l}\text { Felt reaffirmed that other instructors were dealing } \\
\text { with similar issues }\end{array}$ & NA & 45 \\
\hline \multicolumn{3}{|l|}{ Regarding the Group Follow-Up Discussion } \\
\hline $\begin{array}{l}\text { The discussion helped me think about my own } \\
\text { teaching. }\end{array}$ & NA & 91 \\
\hline $\begin{array}{l}\text { I felt uncomfortable talking about my own teaching } \\
\text { with the group. }\end{array}$ & NA & 0 \\
\hline I enjoyed the group dynamic. & NA & 91 \\
\hline I learned from others' observations and reflections. & NA & 82 \\
\hline The consultants encouraged my personal reflection. & NA & 73 \\
\hline I made a personal connection with my peers. & NA & 27 \\
\hline
\end{tabular}

Note: The response rate for 2008 was 80 percent, and for 2009 , it was 58 percent.

The fellows achieved a greater sense of community, instructors who wanted to engage in multiple observations had more options, and the opportunity to interact with more than one colleague and discipline ultimately created a significantly richer discussion and reflective experience. 
In a similar jump in ratings, 91 percent of the 2009 respondents compared to 38 percent of the 2008 respondents felt that the observation process caused them to engage in critical reflection about teaching in general. We credit the new structure of the guidelines (Exhibit 2.1) and the addition of the formal written element for the improvement in our fellows' self-reflection. When we piloted the model in 2007 , we simply asked the instructors to observe each other and talk with us about what they had observed. We soon discovered that the instructors needed structure and guidance to reap the most benefits from the experience. As a result of the additional structure, their self-reflections were much more thoughtful, and the discussions were deeper and more fruitful.

Feedback was also gathered from current and former fellows by email in which we asked them to answer questions such as, "How did the peer observation process affect your teaching approach or teaching philosophy?" In those exchanges, many fellows listed peer observation among their favorite elements of the program. They similarly found the observation process to be beneficial to their development as effective teachers. One example of these sentiments is expressed in the following statement: "It made me think about what it meant to be a good teacher. It made me think about my role as an instructor and what kind of teacher I wanted to be. It made me think critically about things that I hadn't noticed about myself. I am still trying to work on some of those things."

In regard to interdisciplinary observation, we met with varied reactions from the fellows. Nevertheless, most welcomed the interdisciplinary experience and found it to be highly beneficial, as these examples show:

This disconnect between the observer and the classroom has greater potential to drive both fellows to a deeper sense of reflection because of the lack of familiarity.

The commonalities of teaching in all subjects really spurred me on to make sure I was doing the best job possible for my students.

Overall, as shown in Table 2.1, the fellows found the peer observation process to be a useful way to engage in community and critical reflection, and they enjoyed the disciplinary intersection and the group dynamic. Since adding the peer observation component, we have seen a significant increase in the sense of collegiality and camaraderie within the cohort. 


\section{Discussion}

In dismal economic times, faculty developers cannot underestimate the value of inexpensive programming for offering great impact for young instructors and faculty alike. This model requires no cost beyond the salaries (the "consultants" here are not consultants in the sense that they get paid by the hour; they are employees who refer to themselves as consultants to the process) of the consultants who facilitate its implementation and requires no large facility. Although our groups met in conference rooms in our own teaching and learning center, they could meet anywhere on campus-classrooms, lounges, offices, even the bookstore coffee shop. All that is truly required is willing participation from instructors, time from consultants, a basic spreadsheet to aid in coordinating schedules, and patience during the scheduling process.

The process of observing one another and discussing their beliefs was particularly powerful for young graduate student instructors who are relatively new to the college classroom and still discovering their personal teaching philosophies. However, much literature reveals the importance of collegiality and relationships to the success and satisfaction of both new and experienced faculty (Baldwin, DeZure, Shaw, \& Moretto, 2008; Boice, 1991, 1993; Karpiak, 1997; Sorcinelli, 1992). The self-reflective peer observation process could also be valuable for new faculty members in search of guidance and community, or seasoned midcareer faculty looking to reenergize their teaching. We have seen that instructors are interested in seeing how others "negotiate the classroom terrain and how they resolve challenges similar to those they face daily" (DeZure, 1993, p. 28), finding support and building connections with one another, and discovering that they are not alone in their experiences. As DeZure also notes, the involvement of a teaching and learning center can help structure the peer observation experience and alleviate concerns about intrusiveness for instructors who are interested in observing others but are perhaps reticent to initiate the relationship on their own. Assistance from a faculty developer in the scheduling of observations and meetings can also help avert potential procrastination from busy faculty who might be excited about the idea of peer observations but slow to follow through.

Regarding the reflective process, we have found that ultimately, as Cranton (2006) remarks, "an educator can do nothing to ensure that transformative learning takes place. Learners must decide to undergo the process themselves" (p. 135). Nevertheless, "We do not leave the possibility of students engaging in critical self-reflection, increasing self-knowledge, and potentially transforming perspectives to chance. It is our responsibility 
to help people articulate and examine beliefs and assumptions that have been previously assimilated without questioning" (p. 135). So while we cannot coerce instructors to reflect, we do continue to believe in the value of reflection and that we can help them reexamine their teaching in new ways with a little bit of guidance. We will continue to modify our model toward the goal of promoting deeper thoughtfulness in our instructors and their subsequent growth.

What began for us as a simple invitation to watch others teach has been confirmed as a truly rewarding experience for graduate instructors and an undeniable opportunity for their growth as reflective teachers. By embracing peer observation as a vehicle for self-reflection and community rather than critique and evaluation, fellows become a cohort of thoughtful faculty members who are comfortable engaging in open dialogue about teaching and learning.

\section{REFERENCES}

Allen, R. R. (1991). Encouraging reflection in teaching assistants. In J. D. Nyquist, R. D. Abbott, D. H. Wulff, \& J. Sprague (Eds.), Preparing the professoriate of tomorrow to teach: Selected readings in TA training (pp. 313-317). Dubuque, IA: Kendall/Hunt.

Baldwin, R., DeZure, D., Shaw, A., \& Moretto, K. (2008, September/October). Mapping the terrain of mid-career faculty at a research university: Implications for faculty and academic leaders. Change, 40(5), 46-55.

Barnett, M. A. (1983). Peer observation and analysis: Improving teaching and training TAs. ADFL Bulletin, 15(1), 30-33.

Beaty, L. (1999). The professional development of teachers in higher education: Structures, methods and responsibilities. Innovations in Education and Teaching International, 35(2), 99-107.

Bell, M. (2001). Supported reflective practice: A programme of peer observation and feedback for academic teaching development. International Journal for Academic Development, 6(1), 29-39.

Boice, R. (1991). Quick starters: New faculty who succeed. In M. Theall \& J. Franklin (Eds.), New directions for teaching and learning: No. 48. Effective practices for improving teaching (pp. 111-121). San Francisco: Jossey-Bass.

Boice, R. (1993). Primal origins and later correctives for midcareer disillusionment. In M. J. Finklestein \& M. W. LaCelle-Peterson (Eds.), New directions for teaching and learning: No. 55. Developing senior faculty as teachers (pp. 33-41). San Francisco: Jossey-Bass. 
Brookfield, S. D. (1995). Becoming a critically reflective teacher. San Francisco: Jossey-Bass.

Bullough, R. V., \& Gitlin, A. D. (1991). Educative communities and the development of the reflective practitioner. In B. R. Tabachnick \& K. M. Zeichner (Eds.), Issues and practices in inquiry-oriented teacher education (pp. 35-55). Bristol, PA: Falmer Press.

Chism, N.V.N. (1999). Peer review of teaching: A sourcebook. San Francisco: Jossey-Bass/Anker.

Cosh, J. (1999). Peer observation: A reflective model. ELT Journal, 53(1), 22-27.

Cranton, P. (2006). Understanding and promoting transformative learning. San Francisco: Jossey-Bass.

DeZure, D. (1993). Opening the classroom door. Academe, 79(5), 27-28.

Hammersley-Fletcher, L., \& Orsmond, P. (2005). Reflecting on reflective practices within peer observation. Studies in Higher Education, 30(2), 213-224.

Karpiak, I. E. (1997). University professors at mid-life: Being a part of . . but feeling apart. In D. DeZure (Ed.), To improve the academy: Vol. 16. Resources for faculty, instructional, and organizational development (pp. 21-40). Stillwater, OK: New Forums Press.

Loughran, J. J. (2002). Effective reflective practice: In search of meaning in learning about teaching. Journal of Teacher Education, 53(1), 33-43.

Maas, J. (1991). Writing and reflection in teacher education. In B. R. Tabachnick \& K. M. Zeichner (Eds.), Issues and practices in inquiry-oriented teacher education (pp. 211- 225). Bristol, PA: Falmer Press.

Millis, B. J. (1992). Conducting effective peer classroom observations. In D. H. Wulff \& J. D. Nyquist (Eds.), To improve the academy: Vol. 11. Resources for faculty, instructional, and organizational development (pp. 189-201). Stillwater, OK: New Forums Press.

Millis, B. J. (1999). Three practical strategies for peer consultation. In C. K. Knapper \& S. Piccinin (Eds.), New directions for teaching and learning: No. 79. Using consultants to improve teaching (pp. 19-28). San Francisco: Jossey-Bass.

Posner, G. J. (1989). Field experience: Methods of reflective teaching. New York: Longman.

Richardson, M. O. (2000). Peer observation: Learning from one another. Thought and Action, 16(1), 9-20.

Shulman, L. S. (2000). Teaching as community property: Putting an end to pedagogical solitude. In D. DeZure (Ed.), Learning to change: Landmarks in teaching and learning in higher education from Change magazine, 19691999 (pp. 24-26). Sterling, VA: Stylus. 
Sorcinelli, M. D. (1992). New and junior faculty stress: Research and responses. In M. D. Sorcinelli \& A. E. Austin (Eds.), New directions for teaching and learning: No. 50. Developing new and junior faculty (pp. 27-37). San Francisco: Jossey-Bass.

Weimar, M. (1990). Improving college teaching. San Francisco: Jossey-Bass.

Wilkerson, L., \& Lewis, K. G. (2002). Classroom observation: The observer as collaborator. In K. H. Gillespie, L. R. Hilsen, \& E. C. Wadsworth (Eds.), A guide to faculty development: Practical advice, examples, and resources (pp. 74-81). San Francisco: Jossey-Bass/Anker. 